Peer-Reviewed Article

ISSN: 2162-3104 Print/ ISSN: 2166-3750 Online

Volume 7 Number 1 (2017), pp. 73-93

(C) Journal of International Students

http://jistudents.org/

\title{
Challenges of International Students in a Japanese University: Ethnographic Perspectives
}

\author{
Ju Seong Lee \\ University of Illinois at Urbana-Champaign, USA
}

\begin{abstract}
The author investigates what challenges four international students (Vietnamese, Filipino, Brazilian, and Chinese) faced and how they coped with these dilemmas in a Japanese language program during the first semester in 2014. Multiple apparatuses (e.g., field notes, face-to-face oral interviews, focal group conversations, and semi-structured written interviews) were employed to triangulate the data. The findings show four major challenges: Personal psychological issues, general living issues, sociocultural issues, and Japanese language issues. Additionally, supporting group, positive attitude, interaction with Japanese friends, financial assistance, and useful learning strategies are identified as coping strategies. The results will provide implications for international students as well as language instructors and program coordinators in a higher education institution to better assist the international students.
\end{abstract}

Keywords: Ethnographic research, International students in a Japanese university, challenges during the first semester

In recent years, the population of international students who study abroad has dramatically increased. According to World Education Services (2012), the number of the international students reached more than 3.5 million around the world in 2010, an increase of almost 50 percent from the figure (of 2.1 million) in 2002. More recently, World Education News and Review (2013) released a report that the percentage of international undergraduate enrollment in the four leading countries in 2009 has significantly increased in comparison to the figures of 2002 (e.g., 67\% in Canada, 62\% in the United Kingdom, 43\% in Australia, and 13\% in the United States). As the higher education system is increasingly becoming more internationalized 
and a degree from prestigious foreign countries hold comparative advantages (e.g., higher social status, better professional career, networking opportunities), the number of international students is expected to continuously increase for years to come (Ghazarian, 2014; Lee \& Brinton, 1996; Varghese, 2008; Wenhua \& Zhe, 2013).

As the number of international students is on the rise, a variety of problems and challenges involved in overseas study also occurs (Andrade, 2006; Gebhard, 2012; Huang, 2004; Huang \& Brown, 2009; Li et al., 2014; Lin \& Scherz, 2014; Marui \& Lee, 1995; Murphy-Shigematsu \& Lee, 1999; Murphy-Shigematsu \& Shiratsuchi, 2001; Murphy-Shigematsu, 2002; Roy, 2013; Wenhua \& Zhe, 2013). Based on the documentary analysis, for instance, Wenhua and Zhe (2013) identify five major adjustment problems international students face in foreign countries: personal psychological issues, academic issues, sociocultural issues, general living issues, and language proficiency.

According to University World News (2012), the most popular destination with the number of international students was the United States (19\%), followed by the United Kingdom (11\%), Australia (8\%), France (7\%), Germany (6\%) and Japan (4\%). Therefore, it may seem plausible that a majority of the research on the challenges facing international students is concentrated on the top three destinations, namely the United States, the United Kingdom, and Australia (Andrade, 2006; Gebhard, 2012; Huang, 2004; Huang \& Brown, 2009; Li et al., 2014; Lin \& Scherz, 2014; Marui \& Lee, 1995; Roy, 2013; Wenhua \& Zhe, 2013). However, several scholars have also maintained that the research on the challenges of international students in non-English speaking countries is still in its infancy and should receive more attention (Ikeguchi, 2012; Jou \& Fukada, 1996; MurphyShigematsu \& Lee, 1999; Murphy-Shigematsu \& Shiratsuchi, 2001; Murphy-Shigematsu, 2002; Tamaoka et al., 2003).

Recently, the Japan Student Services Organization (JASSO) (2014) released a report on trends for a number of international students. In 1993, there were 48,560 international students in Japan. In 2003, this figure increased to 109,508. By May of 2013, the total number of international students in Japan was 135,519. If international students enrolling in Japanese language institutes are included, this figure rises to 168,145. Although Japan's share of international students seems disproportionately lower than in western countries (e.g., the United States, the United Kingdom), Japan is the top destination in Asia. However, little research has been conducted on adjustment issues among international students in Japan. In particular, almost no attention has been paid to international students in a Japanese context in the Journal of International Students. To fill these gaps, this ethnographic study aims to examine the adjustment problems and coping strategies identified and experienced by international students in a 
Japanese university during the first semester in 2014. The findings of this study will provide insights and implications for international students as well as language instructors and program coordinators in a Japanese university, to better understand the international students.

\section{LITERATURE REVIEW}

\section{Challenges of International Students in English-speaking Countries}

In the published literature, there are a variety of definitions of international students. In this study, the definition of international students is adopted from Andrade's (2006) study as defined as "individuals enrolled in institutions of higher education who are on temporary student visas and are non-native speakers” (p. 134). In particular, the author distinguishes international students by their nationality (e.g., Chinese, Brazilian) and provides more details when necessary.

As the higher education system is increasingly becoming more internationalized, and a degree from prestigious foreign countries holds comparative advantages (e.g., higher social status, better professional career, networking opportunities), the number of international students has been dramatically on the rise for the past decade (Ghazarian, 2014; Lee \& Brinton, 1996; Varghese, 2008; Wenhua \& Zhe, 2013). For instance, the World Education News and Review (2013) reports that the percentage of international undergraduate enrollment in the four leading countries in 2009 has significantly increased in comparison to the figures in 2002 (e.g. 67\% in Canada, 62\% in the United Kingdom, 43\% in Australia, and 13\% in the United States).

As the population of international students has increased, several problems and challenges in relation to studying abroad have been also identified (Andrade, 2006; Gebhard, 2012; Huang, 2004; Huang \& Brown, 2009; Li et al., 2014; Lin \& Scherz, 2014; Marui \& Lee, 1995; MurphyShigematsu \& Lee, 1999; Murphy-Shigematsu \& Shiratsuchi, 2001; Murphy-Shigematsu, 2002; Roy, 2013; Wenhua \& Zhe, 2013). For example, several studies have researched the challenges that international students face in English-speaking countries. Andrade (2006) explored what influences the adaptation and academic achievement of international students had been, based on a documentary analysis of published literature. The findings suggest that international students had more difficulty adjusting to new academic and social environments, in contrast to domestic students. In particular, the academic challenges for international students are associated with language issues, which can negatively affect their emotions (e.g., embarrassment, disappointment and boredom). As a coping strategy, international students need to seek help from English language support programs. In terms of social adjustment, international students have more 
difficulty than domestic students because of the absence of a close inner circle group (e.g., family and close friends), which could lead to loneliness and homesickness. Social support and having friendships with domestic students can help international students cope with social adjustment issues.

Gebhard (2012) investigated the types of adjustment issues among 85 international students at an American university, through interviews, observation field notes and students' self-reports. The findings indicate that students were challenged by academic, social, and emotional difficulties in the new environment. He indicated that international students were not familiar with social and cultural norms, which could negatively affect social interaction in America. As a coping strategy, the study suggests that international students establish supporting groups with co-nationals or friends who share similar cultural backgrounds. Additionally, interaction with domestic students is encouraged as a means of coping with adjustment challenges, which positively influences students' satisfaction with life and learning.

Lin and Scherz (2014) conducted a study on linguistic and cultural challenges that five Asian international graduate students encountered in an American university. Drawing on interviews and focal group conversations, the findings suggest that understanding lectures, as well as participation on discussions posed linguistic challenges to the international students. Regarding cultural challenges, most participants struggled due to a lack of opportunities to interact with domestic students. To overcome linguistic difficulties, participants employed a variety of strategies (e.g., recording lectures, self-talk in English, talking with native speakers in the cafeteria). They also coped with cultural challenges by traveling to other places, attending church services and learning about American sports from American friends. The researchers called for pedagogical change among instructors by adopting more linguistically and culturally sensitive methods of instruction for the international students.

Roy (2013) discussed learning difficulties experienced by Asian international students (e.g., Chinese, Japanese, and Korean) in the United States due to the language barrier. As a solution, he suggested that American professors should be more responsible for employing culturally responsive pedagogical strategies in the classroom. For example, it would create more optimal classroom atmosphere for international students if instructors incorporated emotional intelligence (Goleman, 1998) into their teaching by being more self-aware, motivated, and empathic. He also stressed the importance of 'the respectful mind' (Gardner, 2007), which "welcomes differences between human individuals and between human groups, tries to understand these 'others,' and seek to work effectively with them” (p. 3).

There has been research that focuses on adjustment issues facing Chinese students at North American universities (Huang, 2004; Huang \& 
Brown, 2009). Due to a different cultural background (e.g., Confucian philosophy) and educational system (e.g., a test-driven system), Chinese students struggle greatly in learning and participating in the classroom, which creates stress and anxiety. For instance, Chinese teachers are so influential in the classroom due to the Confucian belief that Chinese students simply follow teachers' pedagogy (e.g., lecture-based instruction) as a model of knowledge and view their teacher as a lifetime master. Unlike China's instructional style, American professors tend to emphasize classroom discussions, which play a negative role in Chinese students' learning. As implications for education, the researchers emphasize the importance of creating a culturally sensitive classroom environment (e.g., lecture style, with accompanying teaching materials).

$\mathrm{Li}$ et al. (2014) conducted a systematic review of 18 studies on psychological wellbeing among East Asian international students. A majority of the studies $(n=13)$ look at Chinese international students and identify several variables such as multicultural competence (e.g., English proficiency, intercultural competence), sociocultural factors (e.g., acculturation, discrimination), and psychological factors (e.g., anxiety, homesickness) that affect the psychological status of Asian international students

Wenhua and Zhe (2013) also conducted a systematic literature review to identify international students' adjustment issues in Englishspeaking countries (e.g., the United States, the United Kingdom, New Zealand, and Australia). They provided a summary of problems experienced by international students, with five categories (e.g., personal psychological issues, academic issues, sociocultural issues, general living issues, and English language proficiency) and specific problems (e.g. financial problems, homesickness, cultural shock).

\section{Challenges facing International Students in Japan}

Unlike English-speaking countries such as United States (19\%), the United Kingdom (11\%), and Australia (8\%), Japan ranked as the sixth-mostpopular location (4\%) for international students (University World News, 2012). Although Japan's share of international students seems disproportionately lower compared to the western countries, Japan is the top-notch destination in Asia. Recently, therefore, a growing number of studies have paid attention to the challenges of international students in nonEnglish speaking countries, specifically in a Japanese university context, although such studies are still in their infancy (Ikeguchi, 2012; Jou \& Fukada, 1996; Murphy-Shigematsu \& Lee, 1999; Murphy-Shigematsu \& Shiratsuchi, 2001; Murphy-Shigematsu, 2002; Tamaoka et al., 2003).

Murphy-Shigematsu and Lee (1999) and Murphy-Shigematsu (2002) carried out a survey on challenges facing Korean students ( $\mathrm{n}=96)$ in 
Japan, at Japan's national university. The findings show that Korean students have difficulties due to financial hardship, the perceived value of a degree from Japan (in comparison to a similar degree from the United States), and attitudes toward Japanese society and inter-cultural relationships with Japanese people. This study further analyzed and highlighted the characteristics of the psychological struggles of Korean international students in Japan. The data suggests that Korean students feel prejudiced against and discriminated toward by Japanese people, most likely due to the nature of Japan's 'strong sense of group-consciousness (shudan-shugi)' (Murphy-Shigematsu, 2002, p. 78), which tends to make groups or communities exclusively for Japanese people. Korean students perceive this closed (heisateki) and discriminatory Japanese way of thinking and behavior as hindrances to their general quality of living and study in Japan. Additionally, some Korean students find it difficult to interact with Japanese due to a discrepancy between true feelings (honne) and formal behavior (tatemae), even though they share the similar cultures. To Koreans, this gap between how they feel and how they behave is seen as insincere and even offensive.

There was one study done on international students with family dependents in Japan (Murphy-Shigematsu \& Shiratsuchi, 2001). The results showed that they are mostly challenged by factors related to accommodation, language barrier, and children's education. The researchers argued for more proper support and assistance for international students studying and living in Japan.

Ikeguchi (2012) conducted a survey with 100 Chinese students in several Japanese universities regarding their adjustment problems. The results show that a majority of international students believed that Japanese language is difficult to understand and use (81\%). In addition, $77 \%$ of the respondents said classes were not interesting and enjoyable. Sixty-seven percent of them answered that it was difficult to get a part-time job in Japan (67\%). Surprisingly, more than half of the respondents (55\%) believed that Japanese people do not like foreigners. The researcher argued that Japanese institutions do not properly address these issues raised by international students studying in Japan. Additionally, the authors concluded that more financial assistance, psychological and social assistance, and intensive culture training are needed to better accommodate international students in Japan.

Considering the trends in the number of international students in Japan (from 48,560 in 1993, up to 168,145 in 2013), more research on this critical issue is required (Japan Student Services Organization, 2014). In particular, it is unfortunate that in the Journal of International Students almost no attention has been paid to international students in the Japanese context. To fill these gaps, this ethnographic study aims to examine the 
adjustment problems and coping strategies identified and experienced by international students in a Japanese university during the first semester in 2014. The findings of this study will provide insights and implications for international students as well as language instructors and program coordinators in a Japanese university setting, to better understand international students.

\section{RESEARCH METHOD}

\section{Research Questions}

1. What challenges do international students in a Japanese university experience during the first semester of their course of study?

2. What strategies do they employ to cope with these challenges?

\section{Setting and Participants}

Ethnographic research was conducted from March to August 2014 in and outside of class in a Japanese language program operated by a major private university in Tokyo. This language program was aimed primarily at non-native speakers of Japanese, providing a core Japanese language course, with subjects with a specific focus (i.e., speaking, listening, reading and writing). It also offered a range of subjects in Japanese studies such as Japanese studies on society and culture, as well as optional subjects presented in lecture format, in English.

The author (hereafter referred to the 'first-participant') was assigned to Level 1 or beginner level. The class took place on Monday, Wednesday, and Friday for three hours, respectively. The curriculum was very systematic and well organized. For example, every class began with dictation, vocabulary, grammar, and Kanji (a Chinese character) test. Monday and Wednesday classes focused on conversation practice, while Friday classes concentrated on grammar explanation. Students were given homework for each class.

In the initial stage of this research, I intended to focus on nine international students who studied in the same classroom but who had diverse personal and professional backgrounds. After a month, however, I decided to narrow down the participants to four (Vietnamese, Filipino, Brazilian, and Chinese) because these participants seemed to be struggling greatly in a distinctive but somehow similar pattern. For instance, all of them had a successful professional career at their respective home country, but felt disparaged in Japan during the first semester of their study period due to a variety of adjustment issues. Table 1 displays the basic profile of the participants in this study. To protect the subject's privacy, I used pseudonyms for them after consulting with each participant. 
TABLE 1. Basic profile of the participants

\begin{tabular}{|c|c|c|c|c|}
\hline Name & Nationality & Age & Purpose of Studying Japanese & Profession \\
\hline Smith & Philippines & 26 & $\begin{array}{l}\text {-Enter graduate work in Japan } \\
\text {-Teach English in Japan }\end{array}$ & $\begin{array}{l}\text { University } \\
\text { Instructor }\end{array}$ \\
\hline Liu & China & 27 & $\begin{array}{l}\text {-Improve professionally } \\
\text {-Enter MBA program }\end{array}$ & Accountant \\
\hline Mickey & Brazil & 31 & $\begin{array}{l}\text {-Get government grants } \\
\text {-Take graduate work }\end{array}$ & Finance Manager \\
\hline Chu & Vietnam & 32 & $\begin{array}{l}\text {-Get Government grants } \\
\text {-Take graduate work }\end{array}$ & Ophthalmologist \\
\hline
\end{tabular}

\section{Data Collection and Analysis}

To accomplish these objectives, I employed four instruments (i.e., field notes, face-to-face oral interviews, semi-structured online interviews, and focal group conversations) to triangulate the data and thereby attain a higher level of reliability of the data. The study was carried out from March to August 2014. I used an ethnographic approach, the characteristics of which are summarized in Table 2. Based on Nunan's (1992) summary of the main features of ethnographic research, I closely observed and interacted with the participants in various "informal" natural settings to understand their "genuine" challenges.

TABLE 2. Characteristics of ethnographic research (from Nunan, 1992, p. 56)

\begin{tabular}{ll}
\hline \hline Characteristic & \multicolumn{1}{c}{ Gloss } \\
\hline Contextual & $\begin{array}{l}\text { The research is carried out in the context in which the } \\
\text { subjects normally live and work. }\end{array}$ \\
Unobtrusive & $\begin{array}{l}\text { The researcher avoids manipulating the phenomena under } \\
\text { investigation. } \\
\text { Longitudinal }\end{array}$ \\
The research is relatively long-term. \\
Interpretive & $\begin{array}{l}\text { The research involves the participation of stakeholders } \\
\text { other than the researcher. }\end{array}$ \\
Organic & $\begin{array}{l}\text { There is interaction between questions/ hypotheses and } \\
\text { data collection/ interpretation. }\end{array}$ \\
\hline
\end{tabular}

The ethnographic approach was beneficial because I could get to know the participants closely and understand their struggles at a deeper level, which allowed me to interpret the data more accurately. At the same time, I conducted 'informal' oral interviews with the participants in various real-life contexts (i.e., classrooms, restaurants, cafés, tourist attractions, and a hot spring), which caused me to re-check my understanding of the data and 
helped me obtain additional authentic information. All data obtained through observation and informal oral interviews were recorded in blogs as field notes. In July 2014, I conducted and moderated a focus group conversation session for two hours in order to clarify the data for an accurate and deeper level of analysis. Unlike the informal interview, the participants gathered together at one place to discuss given topics. From July to August 2014, I interpreted the data by juxtaposing it with other research and conducted semi-structured online interviews with the participants by email and by social media (e.g., Facebook).

TABLE 3. Summary of adjustment issues faced by international students (modified and adopted by Wenhua \& Zhe, 2013)

\begin{tabular}{ll}
\hline Category & Specific problems \\
\hline Personal psychological & Homesickness, loneliness, stress, depression, \\
& frustration, loss of status or identity, anxiety, \\
& confusion, etc. \\
\hline Sociocultural issues & Cultural shock, cultural fatigue, stereotyping, \\
& prejudice, racial discrimination, difficulties in \\
& adjusting to new social/cultural customs, \\
& norms and regulations and participating in \\
& intercultural/social activities, relationship \\
& problems, etc. \\
\hline General living issues & $\begin{array}{l}\text { Accommodation difficulties, difficulties in } \\
\text { using student support services, financial }\end{array}$ \\
& stress, dietary restrictions, safety threats, etc. \\
\hline Japanese language issues & $\begin{array}{l}\text { Difficulties in communicating with native } \\
\text { speakers, understanding lectures, writing up } \\
\text { essays, etc. }\end{array}$ \\
\hline
\end{tabular}

\section{FINDINGS AND DISCUSSION}

\section{Challenges faced by International Students}

\section{Smith}

Smith is 26-year-old Filipino. Before coming to Japan, he taught philosophy and English literature in a Filipino national university. He was studying Japanese for two reasons: to enter a graduate school and teach English in Japan.

During the first semester, Smith suffered from factors related to general living issues and sociocultural issues. Regarding general living issues, one of his greatest challenges was financial stress due to unstable financial support. In this aspect, he was fortunate because in March of 2014 he found a fine Filipino host family, which charged decently low rental fees. 
According to my field note (March, 2014), he only paid \$350 per month for accommodation, including electricity, water, and a Wi-Fi Internet connection, which was almost twice as cheap as the average such rental fee in Tokyo. However, there also were some disadvantages concerning this budget accommodation, as described in Excerpt 1.

Excerpt 1. Semi-structured interview regarding 'Financial stress' (August, 2014)

The only complaint I had was its unfavorable location. At the beginning of the semester, I was often late for the class. That is because I had to take a bicycle from home to the nearest station, take a subway, and transfer to another subway line, get off a train, and walk all the way to the school. In total, it took me around 90 to 120 minutes just to go to school.

During the focal group conversation conducted in July 2014, he also shared some painful anecdotes about how the unfavorable location of his accommodation negatively affected his level of academic achievement. For instance, he did not have enough time to study the Japanese language, as he spent almost three hours merely commuting between home and school, in addition to working more than 25 hours a week. Also, he would have no time to practice Japanese conversation simply because he had no time to meet or interact with native Japanese speakers. Finally, his struggle became more severe over time. This is consistent with my field note that shows how Smith was struggling due to his unstable financial situation, as illustrated in Excerpt 2.

Excerpt 2. Field note regarding 'Financial stress' (May, 2014) Fortunately, he found a job nearby his home and worked in a noodle-manufacturing factory every Tuesday, Thursday, and Saturday. But he also applied for a few other job interviews to secure the financial source. He was extremely concerned about his tuition in the next semester already, so he applied for a scholarship last April. This month [in May], it seems that he still struggled between studying Japanese and working for securing his stable finance.

This finding is supported by previous studies (Li et al., 2014; Murphy-Shigematsu \& Lee, 1999; Murphy-Shigematsu, 2002; Wenhua \& Zhe, 2013). Unlike other participants in this study, he was a privately funded student and had to strike a balance between doing a part-time job and studying Japanese. In fact, he would not have enough time to study Japanese on the days he worked because he became physically exhausted at the end of 
each work day. Regarding sociocultural issues, he experienced stereotyping and racial discrimination while living in Japan, as described in Excerpt 3.

Excerpt 3. Semi-structured interview regarding 'stereotyping and racial discrimination' (August, 2014)

I find the logic like this in terms of discrimination in job employment. Japanese firms with Western interviews kind of discriminated and preferred to choose Westerns for one sole reason: They think the Japanese would prefer that.

The previous studies have also supported this finding (MurphyShigematsu \& Lee, 1999; Murphy-Shigematsu, 2002; Wenhua \& Zhe, 2013) as some international students report they feel Japanese are biased and discriminatory toward different nationalities. According to field notes (May, 2014), he also mentioned that there was discrimination by some companies in Japan that were handled by Caucasians. He said he felt that these companies seemed to find non-Caucasian less appealing than Japanese. On the other hand, he obtained an English teaching job in a Japanese firm. For Japanese job interviewers, he believed that as long as he "could speak good English they were okay with it.” Caucasian employers in Japan might have had a perception of Standard English because he exhibited some accent, which is often "an implicit code for race or ethnicity" (Tollefson, 2002, p. 150). Discrimination based on accent, however, can be problematic and may stir up racism. The employers devalued other varieties of English (e.g., Filipino English) in that it differs from so-called Standard English in pronunciation and some linguistic features.

\section{Liu}

Liu is a 27-year-old Chinese woman. She was born and educated in a small country town in China. After obtaining her B.A. in business administration in 2009, she worked as an accountant in a large multinational corporation, until February 2014. She decided to leave her profession and come to Japan to study Japanese for two reasons: first, she wanted to improve herself professionally. Second, she wanted to pursue an MBA degree in a Japanese graduate school—after achieving a certain level of Japanese proficiency.

During the first semester, Liu was challenged due to Japanese language issues and personal psychological issues. Regarding Japanese language issues, she struggled linguistically for the first month of her study in Japan because she had difficulties in communicating with others both in English and Japanese, as described in Excerpt 4.

Excerpt 4. Semi-structured interview regarding 'Japanese language issues' (August, 2014) 
I feel the first month (April) in Japan was hard and confusing. The hardest part was language. In April, I knew nothing about Japanese. I did not know Hiragana. In the beginning of the semester, teachers explained everything in English. Since my English was poor, I could not understand them well. I felt anxious and frustrated. Even when I had to talk with my classmates, I also had to speak in English. Because of language, I had lots of difficulties in adjusting to this new school life.

During the focal group conversation, I asked her why she did not study foreign languages (e.g., English and Japanese) until she came to Japan. She responded with two answers: first, she was not talented in learning foreign languages. Second, she had no need to learn a foreign language in the company because of her job (e.g., accountant). Considering the fact that Liu had been living in a small country town in China for her entire life up to the point that she left it to enroll in school elsewhere, and Japan was the first foreign country she ever visited, it seemed evitable she would initially struggle greatly in area of language.

Although Liu struggled linguistically in April, over time she began to speak Japanese and English fluently with a high degree of accuracy. Especially in the classroom setting, she was confident in her command of Japanese. According to field notes (June 2014), she was one of the best students in the classroom and seemed confident, with a good command of Japanese. However, she still had difficulties in communicating with native Japanese speakers outside the classroom, as depicted in Excerpt 5.

Excerpt 5. Semi-structured interview regarding 'Japanese language issues' (August, 2014)

At the third month of school, I already adapted to the new school life. The greatest improvement was I could speak some basic Japanese, which made my daily life more convenient. But when I went to visit Japanese language program office to ask something about scholarship, I was frustrated because I could not communicate with the Japanese staff in Japanese. I was shocked and very stressed out. Because of the limited language proficiency, I could not express myself properly and couldn't get the information I wanted.

Excerpt 5 was intriguing because Liu still struggled in everyday conversation outside of the classroom, although she improved her Japanese language proficiency and thus was regarded as the best Japanese speaker by her classmates. The field note (June 2014) recorded that toward the end of the semester, Liu became more vocal, with diverse Japanese structures and vocabularies. However, according to Excerpt 5, a foreign language learned 
in the classroom cannot be always translated into communicative competence outside the classroom, which can make language learners feel frustrated and challenged. This finding is congruent with a finding from the study done by Andrade (2006), in which international students had difficulties adjusting to new academic and social environments, most likely due to language issues, which can negatively affect their emotions (e.g., embarrassment, disappointment and boredom), as well as their level of academic achievement.

Regarding personal psychological issues, their appearance could have been inevitable because it was her first overseas trip and longest period ever away from her family. In light of Andrade's study (2006), her challenge involving Japanese language issues could make her feel lonely and disappointed, which could exacerbate her psychological issues. In Excerpt 6, Liu did point out that she felt lonely and homesick, but that her Chinese friends living in the same area helped her tremendously.

\section{Excerpt 6. Semi-structured interview regarding 'Personal psychological issues' (August, 2014) \\ If I did not need to go to school, most of time I stayed with new Chinese friends who gave me lots of help to adjust to the new life in Tokyo. Because of them, I did not feel lonely and did not miss my hometown as much as before.}

During the focal group conversation, Liu confessed that she missed her parents very much when the result of her attempt to speak Japanese did not go well. In June, she even began to doubt whether her decision to study Japanese was correct. Her Japanese was not as fluent as she had hoped based on her previous efforts, and over time, she knew that studying in a foreign country would not be easy. In this aspect, Li et al.'s study (2014) indicates that East Asian students are more likely to improve in the target language if they remain in the host country for a longer period of time, which can lead to mitigating the level of personal psychological stresses and anxieties.

\section{Mickey}

Mickey is 31 years old. Mickey was one of the most elite students in the classroom. Ostentatiously, he earned three bachelor's degreesin advertisement, social science, and economics-at one of the best national universities in Brazil. He had worked as a manager in a major bank in Brazil for ten years. He came to Japan through a Japanese government scholarship program. His goals for studying in Japan were three-fold: First, he wanted to improve his Japanese and English abilities; second, he wanted to earn a M.A. in economics at this university; third, he wanted to thoroughly 
experience Japan and Asia and thereby obtain a more thorough perspective about Asia. His younger brother studied for six years and earned M.A. and Ph.D. degrees from a major Japanese university. He encouraged Mickey to study abroad in Japan and introduced him to some of his personal and working networks.

Considering his academic achievement, clear goals for study, and extensive networking in Japan (thanks to his younger brother), it seems apparent that Mickey would successfully assimilate into Japan. During the first semester, however, Mickey was challenged due to Japanese language and sociocultural issues. Regarding Japanese language issues, he struggled greatly in the classroom at the beginning of the semester. According to field notes (March, 2014), he arrived and attended a Japanese language class one week after the program started, so that he skipped three classes and was already behind in comparison to the rest of his classmates. He confessed that the most difficult period of his life in Japan was the beginning stage, as described in Excerpt 7.

Excerpt 7. Semi-structured interview regarding 'Japanese language issues' (August, 2014)

The most difficult period of my life in Japan was at the beginning stage. I did not know any Japanese character (e.g. Hiragana, Katakana, Kanji) at all. I studied eight hours a day to catch up and it was in vain.

According to the field note (March, 2014), on the first day when I met him, he told me that he was still struggling with 'jet lag.' Also, his Brazilian friends and his brother repeatedly told him that this Japanese language program would be easy, with many fun and intercultural activities - all of which made him frustrated and embarrassed because it was anything but fun. During the focal group conversation, he said, "My first month in Japan was very busy and confused, mainly because in the end nobody could explain to us what was happening." A field note record in April 2014 indicated that his linguistic struggle became more serious and noticeable. For instance, nearly one month after the semester started, Mickey did not even know how to properly pronounce a word, whereas his classmates could already command an effective everyday conversation. So, the program provided him with extra Japanese classes, but did not help him catch up on weeks of missing classes. After all, the enormous workload and intensity of this Japanese language program overwhelmed him. Finally, he decided to study in a lower-level class (0.5 Level), which was created expressly for him. Technically, he dropped the course. But he could come to our class every Friday for grammar class. His difficulty in learning Japanese language lasted until the end of the semester, as described in Excerpt 8. 
Excerpt 8. Field note regarding 'Japanese language issues' (July, 2014)

On July 4, 2014 ('Grammar class' on Friday), he went out in the first period (9:00-10:30 am) and did not come back until the recess. His eyes were red. I assumed he cried. Later, he said, "I do not want to take class in the second period. I have many other things to do. I can't concentrate!” After all, he did not come back on the second period nor attend the last class.

Another challenge he encountered was related to the difficulty in understanding Japanese culture. According to the semi-structured interview, he candidly shared his struggle about understanding the totally different culture of Japan, as indicated in Excerpt 9.

Excerpt 9. Semi-structured interview regarding 'Sociocultural issues' (July, 2014)

I admit that this Japanese program curriculum is very well organized and structured. Teachers did their best to make us successfully acquire Japanese language. But I was not happy about Japanese culture. It is very inflexible but often works according to the manual. I am very flexible and spontaneous so I find it difficult to understand and study under this cultural environment.

Excerpt 9 is pedagogically significant in that none of the Asian participants in this study made mention of this cultural difficulty. For instance, Mickey is extremely extroverted and outgoing, so he had already made a lot of Japanese friends during the first semester. According to one field note (July, 2014), Mickey was also a culturally competent individual, as he had traveled, by his count, to more than 51 different countries at the time of this research. However, the difficulty he had may have been due to Japan's classroom culture, which Mickey had not previously experienced. From my observations and interviews, Mickey possessed a great sense of social intelligence, intercultural competence and linguistic ability. Nonetheless, in the classroom he looked utterly helpless and frustrated. According to semi-structured interview, he confessed he only put 20 percent of his effort into the class. As could be inferred from Excerpt 9, the instructor's "inflexible" teaching style and curriculum might have played a negative role in Mickey's classroom performance. In order words, Mickey is a typical field-dependent person and a frequent risk-taker in terms of learning, but his "linguistic guess" was not fully accepted in the Japanese classroom. He felt unsafe and uncomfortable in this environment, which also might not only have affected his Japanese language learning but also 
caused severe cultural fatigue. He would have adjusted to this new set of customs much easier if he had known that teachers were accustomed to holding absolute authority and are not challenged by students in Japanese culture, which markedly differed from higher education in Brazil (Ariza, 2010). Pedagogically, it is important for language instructors in Japan to establish a classroom atmosphere of acceptance (although it is against the cultural norm), where second language learners can freely make linguistic mistakes, a point Dufeu (1994) made-namely, that language learners should be encouraged to take risks without feeling embarrassed.

\section{Chu}

Chu is a 32-year-old Vietnamese woman. She was an ophthalmologist in Vietnam and was sent to Japan by the Vietnamese government to further her studies. Her primary goal for studying Japanese was to take coursework (lectured in Japanese) in graduate school. She took a Japanese language class every Monday, Wednesday, and Friday while working in the university-affiliated hospital on Tuesday and Thursday. Although she was a proficient English speaker, in the hospital she would need to use Japanese predominantly because a majority of the faculty and students were Japanese.

For the first semester, Chu had difficulties in terms of general living and sociocultural issues. Concerning general living issues, Chu struggled greatly in the early period of her new school life. According to one field note (April 2014), she had several factors to deal simultaneously, such as new accommodations, a new language, a new culture, new food, a new school, new people, and necessary administrative work (e.g., being issued an insurance card, registering her residency, buying a phone). Additionally, she had to work in the hospital twice a week, which was located at a different campus. She wanted to complete all these tasks at once, which caused physical fatigue and sleep deprivation, as indicated in Excerpt 10.

Excerpt 10. Semi-structured interview regarding 'General living issues' (August, 2014)

I arrived [in] Japan on April $2^{\text {nd }}$ and the day after that started Japanese class. I had very little time for rest but had to hastily settle down for new life. My first two weeks in Japan was exhausted and sleep-deprived.

In addition, Chu had to suffer from sociocultural issues for the entire semester. When asked to describe her struggle in Japan during the focal group conversation session, she used the words "frustration and anxiety"-especially in relation to her experience in a Japanese hospital. In Excerpt 11, Chu depicted her struggle while doing research at the hospital. 
Excerpt 11. Semi-structured interview regarding 'Sociocultural issues' (August, 2014)

When I started going my lab twice a week, the time of frustration and anxiety began. Language barrier and new working environment made me feel like I was lost. Not to mention the amount of new knowledge that I need to consume, I was also vague about my future research plan, which made me frustrated. I really didn't know what to do, how to deal with a whole new group of people with different work etiquette that I've never encountered before. I couldn't talk to anyone and I felt like I didn't belong here. That feeling lasted until recently.

Excerpt 11 implies that her struggle was intertwined with several variables, such as the language barrier, a new working environment/culture, pressure about her future research, and isolation. For the entire semester she had to constantly juggle three goals at the same time: learn a new language (in the Japanese language course), learn new content area(s) through the target language (in Japanese hospital), and figure out her future research topic (for her career). Similar to the findings of Murphy-Shigematsu and Lee (1999) and Murphy-Shigematsu (2002), Chu had a hard time in a Japanese hospital due to the cultural complexity of interacting with Japanese people. Considering the nature of Japan's 'strong sense of groupconsciousness (shudan-shugi)’ (Murphy-Shigematsu, 2002, p. 78), which make groups or communities exclusively for Japanese people (as indicated in Excerpt 11), she found it difficult to assimilate and integrate into this small Japanese community (a Japanese hospital) and felt isolated from her Japanese colleagues or other lab members.

\section{Coping Strategies}

The participants in the study employed a variety of coping strategies to overcome the challenges they faced while living in Japan. For coping strategies to overcome personal psychological issues, Chu shared her feelings with others and tried to stay optimistic. Her closest friend was a classmate from Thailand. Outside of class, they spent much time eating, shopping, and conversing. She also spent at least once a week eating out with other classmates and joined in when they went on an outing. In terms of positive mindset, she kept reminding herself of the long-term benefits of what she was undergoing. She mentioned in the focal group conversation that she disciplined herself to stay positive about the task until it is complete. Although she felt discouraged and unsure about encountering several problems and challenges she faced in Japan, she persisted and remained optimistic about her situation. In the case of Liu, her Chinese friends were very helpful in aiding her in adapting to a new environment and 
cope with psychological issues. When there was no class, she stayed with Chinese friends, mostly who were of great help for her in Tokyo. According to the focal group conversation session, she admitted that it was a safe space where she could freely vent her emotional difficulties and travails in her personal life.

When it comes to coping strategies to overcome sociocultural issues, Mickey remained positive about his life in Japan. Although he hit the rock bottom in terms of his Japanese language proficiency in the classroom, he wanted to continue to study until the end. During a focal group conversation, he said, "[I was] very excited about be in Japan and felt prestigious to have this opportunity. Although I was challenged, I believe it will be paid off in the long run.” In addition, Mickey engaged in a variety of activities and spent time socially with Japanese friends. For instance, he joined a language exchange program through which he taught Japanese students Portuguese and they taught him Japanese. In the case of Smith, he could minimize the negative emotions of being discriminated against, as he was living with a Filipino family. During a semi-structured interview (July, 2014), he said he spent a large portion of time watching dramas and movies together with the Filipino family, which helped him stay optimistic about his life in Japan, although there were some sociocultural difficulties. He emphasized the importance of his support group while living in Japan.

With regard to coping strategies to overcome general living issues, Chu mentioned during the focal group conversation session that everything in Japan was almost five times as expensive as in her home country. She often cooked her own dish, which was more delicious and much cheaper. Unlike privately funded students (e.g., Smith), she was a recipient of a government scholarship, which covered her tuition with adequate monthly stipends. In that aspect, she did not have to worry too much about financial constraints.

In terms of coping strategies to overcome Japanese language issues, Smith employed several learning strategies that would meet his situation. Since he did not have enough time to study and practice Japanese, he joined a basic Japanese conversation group in the city hall near his home. He also signed up for a 'conversation partner' program that allowed him to meet and interact with Japanese students on campus on a weekly basis. During the focal group conversation session, he mentioned that he also downloaded several useful Japanese learning apps on his smartphone and studied them in his spare time.

\section{CONCLUSIONS AND IMPLICATIONS}

This ethnographic study attempts to explore what challenges four international students (Vietnamese, Filipino, Brazilian, and Chinese) faced 
and how they coped with these difficulties in a Japanese language program during the first semester of 2014. A variety of instruments (e.g., field notes, face-to-face oral interviews, focal group conversations, and semi-structured written interviews) were employed to triangulate the data. The findings suggest four major challenges: personal psychological issues (e.g., stress, anxiety, loneliness, and depression), general living issues (e.g., financial stress), sociocultural issues (e.g., stereotyping, cultural fatigue), and Japanese language issues (e.g., difficulty in talking with native Japanese speakers). Coping strategies such as support groups, positive attitude, interacting with Japanese friends, financial assistance, and useful learning strategies are identified in the study.

However, some caveats need to be applied to the present study. Above all, the results of this study cannot be generalized since it only examined four international students in one Japanese university. With such a small sample size, the findings may not be transferable to other international students in other contexts. For further research, therefore, more international students in the same or other contexts need to be examined. In addition, the study should probably require longitudinal data to support the findings of this study, in order to increase the credibility and reliability of the data.

To conclude, I would like to provide insights and implications for international students, as well as language instructors and language program coordinators, in an institution of higher education. First of all, international students should be aware of these potential challenges and prepare in advance to effectively handle these issues. It is highly recommended that they secure financial assistance and know about the linguistic and cultural issues beforehand. Second, language instructors should create and adopt teaching methodologies that are more linguistically and culturally sensitive for their international students (Lin \& Scherz, 2014). Also, instructors should try to know students' situations at a personal level and connect with their students through informal (e.g., social media) as well as formal dialogues (e.g., student-teacher conference). Finally, language program coordinators should become more aware of these issues, which present many and varied challenges for international students, and strive to authentically help them, by means of psychological assistance, cultural training, or counseling (Ikeguchi, 2012).

\section{REFERENCES}

Andrade, M. S. (2006). International students in English-speaking universities:

Adjustment factors. Journal of Research in International Education, 5(2), 131-154.

Ariza, E. N. (2010). Not for ESOL teachers: What every classroom needs to know about the linguistically, culturally, and ethnically diverse students ( $\left({ }^{\text {nd }}\right.$ ed.). Boston, MA: Allyn \& Bacon.

Dufeu, B. (1994). Teaching myself. Oxford: Oxford University Press. 
Gardner, H. (2007). Five minds for the future. Boston, MA: Harvard Business School Press.

Gebhard, J. G. (2012). International students' adjustment problems and behaviors. Journal of International Students, 2(2), 184-193.

Ghazarian, P. G. (2014). Actual vs. ideal attraction: Trends in the mobility of Korean international students. Journal of International Students, 4(1), 89103.

Goleman, D. (1998). What makes a leader? Harvard Business Review, 82(1), 82-91.

Huang, J. (2004). Voices from Chinese students: Professors' use of English affects academic listening. College Student Journal, 38(2), 212-223.

Huang, J., \& Brown, K. (2009). Cultural factors affecting Chinese ESL students' academic learning. Education, 129(4), 643-653.

Ikeguchi, T. (2012). Internationalization of education and culture adjustment: The case of Chinese students in Japan. Intercultural Communication Studies, 21(2), 170-184.

Japan Student Services Organization (JASSO). (2014, March 25). International students in Japan in 2013. Retrieved from http://www.jasso.go.jp/statistics/intl_student/data13_e.html

Jou, Y, H., \& Fukada, H. (1996). Comparison of differences in the association of social support and adjustment between Chinese and Japanese students in Japan: A research note. Psychological Reports, 79, 107-112.

Lee, J. T., \& Brinton, M. C. (1996). Elite education and social capital: The case of South Korea. Sociology of Education, 69, 177-192.

Li, J., Wang, Y., \& Xiao, F. (2014). East Asian international students and psychological well-being: A systematic review. Journal of International Students, 4(4), 301-313.

Lin, S.-Y., \& Scherz, S. D. (2014). Challenges facing Asian international graduate students in the US: Pedagogical considerations in higher education. Journal of International Students, 4(1), 16-33.

Marui, E. \& Lee, J. (1995). International students life conditions and stress, University of Tokyo International Center Bulletin, 6, 217-240.

Murphy-Shigematsu, S. \& Lee, J. (1999). Human relations of Korean international students in Japan. University of Tokyo International Center Bulletin, 9, 153-177.

Murphy-Shigematsu, S. \& Shiratsuchi, S. (2001). Supporting international students with families. University of Tokyo International Center Bulletin, 11, 1-24.

Murphy-Shigematsu, S. (2002). Psychological barriers for international students in Japan. International Journal for the Advancement of Counseling, 24, 1930.

Nunan, D. (1992). Research methods in language learning. Cambridge: Cambridge University Press.

Roy, S. R. (2013). Educating Chinese, Japanese, and Korean international students:

Recommendations to American Professors. Journal of International Students, 3(1), 10-16.

Tamaoka, K., Ninomiya, A., \& Nakaya, A. (2003). What makes international students satisfied with a Japanese university? Asia Pacific Education Review, 4(2), 119-128.

Tollefson, J. W. (2002). Language policies in education: Critical issues ( $1^{\text {st }}$ ed.). 
New York, NY: Routledge.

University World News (2012, November 4). New UNESCO interactive map on global student mobility. Retrieved from

http://www.universityworldnews.com/article.php?story=201211021435243

Varghese, N. V. (2008). Globalization of higher education and cross-border student mobility. Paris: UNESCO.

Wenhua, H., \& Zhe, Z. (2013). International students' adjustment problems at university: A critical literature review. Academic Research International, 4(2), 400-406.

World Education Services (2012, February). Trends in international student mobility.Retrieved from http://www.uis.unesco.org/Library/Documents/ research-trends-international-student-mobility-education-2012-en.pdf

World Education News and Review. (2013, March 1). International student mobility trends 2013: Towards responsive recruitment strategies. Retrieved from http://wenr.wes.org/2013/03/wenr-march-2013international-student-mobility-trends-2013-towards-responsiverecruitment-strategies

JU SEONG (JOHN) LEE is a doctoral student at the University of Illinois at Urbana-Champaign (UIUC). His research interests include international student issues, World Englishes, technology-integrated learning in the second/foreign language classroom (via video conferencing, telecollaboration, wearable devices), and self-directed teacher professional development (TPD). Email: jlee682@illinois.edu

Manuscript submitted: April 23, 2015 Manuscript revision submitted: July 13, 2015 Manuscript revised and accepted. August 2, 2015 